\title{
¿Tomar lotes para vivir o para vender? Tráfico de tierras y práctica clientelar en la periferia urbana
}

Sección ESTUDIOS

RECIBIDO: 23/10/2020

APROBADO: 22/11/2020

PUBLICADO ONLINE: 18/12/2020
Nekson Pimentel Sánchez

Universidad Nacional Mayor de San Marcos nekson.pimente@unmsm.edu.pe https://orcid.org/0000-0002-0834-0419

\section{RESUMEN}

Este artículo aborda las relaciones clientelares y su relación con el tráfico de terrenos en las periferias de la urbe limeña. ¿Cuáles son las características y estructura del clientelismo? ¿Cuáles son las formas, agentes y mecanismos del tráfico de terrenos? Estas preguntas permitirán dar cuenta sobre la producción de la ciudad atrapada en una serie de transacciones que puede involucrar a diversos agentes y niveles de especialización en la toma de tierras y la construcción de asentamientos urbanos en la periferia de Lima Metropolitana.

PALABRAS CLAVE: tráfico de tierras; clientelismo; periferia urbana; satélites personales; Lima.

Take lots to live or to sell?

Land trafficking and clientelistic practice in the urban periphery

\section{ABSTRACT}

This article deals with patronage-based relations and their correlation with land trafficking in the outskirts of the city of Lima. What are the characteristics and structure of clientelism? What are the forms, agents and mechanisms of land trafficking? These questions will provide an account of the production of the city caught up in a series of transactions that may involve various agents and levels of specialization in the of land seizing and the construction of urban settlements on the outskirts of Metropolitan Lima.

KEYWORDS: land trafficking; clientelism; urban periphery; personal satellites; Lima. 


\section{Introducción}

I ima Metropolitana pasa por una transformación en su conformación socio espacial. Su crecimiento ha permitido la reducción de zonas productivas por medio de innumerables proyectos inmobiliarios y el desarrollo del tráfico de tierras. A diferencia de la experiencia europea-norteamericana en que la industrialización fue seguida por la urbanización, se produjo una urbanización sin industrialización, generando una masa marginalizada del capitalismo dependiente, con un predominio de un proceso de acumulación enmarcado por la urbanización dependiente (Quijano, 2014), donde se ha generado un nuevo triángulo sin base de carácter propiamente urbano (Durand, 2007), en que es visible, entre otras cosas, la unidad de la cúpula, nuevas elites transgresoras, predominio de clase media y del pueblo autoempleado sin constitución de una colectividad y, más bien, fracturada, sumada a la neutralización del poder formal por agentes de las economías y estructuras delictivas caracterizadas por su conexión con la violencia e involucrados con la modelación de la ciudad.

El tráfico de tierras es un fenómeno de vital importancia para comprender estos cambios, ya que es una vía fundamental en la producción y la gestión de la ciudad en el Perú de nuestros tiempos. Es importante tomar en cuenta el fenómeno a partir de los intereses y prácticas de los actores, las relaciones que se establecen entre ellos y los mecanismos y procedimientos que sirven de soporte, ya que estos cambios también pueden estar asociados a un proceso de individuación (Calderón, 2016), a la constitución de subalternos autónomos (Pimentel, 2017) y el individualismo metonímico (Martuccelli, 2015), donde la lógica pragmática es preponderante y una constante en búsqueda de beneficios y favores.

La producción de la ciudad está atrapada en las transacciones del mercado, esto es, la compraventa de bienes sustentada en la economía de mercado, y un control de precios basado en la oferta y la demanda localmente definido (Molina y Valenzuela 2006). El tráfico de tierras implica que, después de la toma, haya un proceso de intercambio, un proceso de mercantilización del lote por dinero; el lote se convierte en una "mercancía" e indisociable al clientelismo y a la estructura delictiva, ya que el proceso de acumulación y compraventa del lote se vincula con la violencia de mafias organizadas y otros agentes que participan mediante el intercambio de favores, tanto para asegurar la tenencia como para lograr su reconocimiento mediante instrumentos de formalización como las constancias de posesión municipales. Esta práctica puede involucrar a diversos agentes y niveles de especialización, en tanto puede ser sistemático o circunstancial. Esta práctica 
posee un carácter local y específico, e instancia estructural de relaciones de interdependencia basadas en el clientelismo.

Se considera importante investigar la naturaleza que tienen las actuales ocupaciones vinculadas al tráfico de terrenos. ¿Cuáles son las características y estructura del clientelismo?, ¿Qué influye en la decisión de los diversos agentes urbano que forman parte de la práctica clientelar, y qué relación tiene con el tráfico de terrenos? ¿Cuáles son las formas, agentes y mecanismos del tráfico de terrenos?

Si bien estos fenómenos son indisociables de la producción de las ciudades actuales en el Perú, para los propósitos del presente artículos se considerarán básicamente etnografías sobre las periferias urbanas, en especial los procesos de expansión urbana por zonas productivas ubicadas en el centro poblado de Punchauca, así como la expansión del Tercer Sector de El Progreso, distrito de Carabayllo, por laderas que forman parte del territorio de la comunidad campesina de Jicamarca. Se consideran las dinámicas y elementos de las tomas de tierras y formación de asentamientos urbanos desde el 2012 hasta el 2020 en esos espacios situados en la margen izquierda de la cuenca del Chillón.

Metódicamente la investigación estuvo centrada en el uso de técnicas propias de la antropología y la metodología cualitativa, como la observación participante, entrevistas estructuradas, diarios de campo y la revisión de documentos de archivos. La observación participante permitió recopilar información de manera más directa y cercana, mediante participación en reuniones y demás actividades de la Asociación Juventud Solidaria de Carabayllo. Para las entrevistas e historias de vida se hizo una selección de informantes como integrantes de la junta directiva, miembros más antiguos del asentamiento, coordinadores de sectores, parceleros y algunas promotoras de venta de las inmobiliarias. La documentación giró propiamente en la revisión de los libros de acta y mapas del asentamiento.

\section{Contexto sociohistórico y la política de subalternos autónomos}

La producción de la ciudad en el Perú está vinculada al mercado ilegal del suelo, sostenido por un conjunto de procesos y la presencia de múltiples agentes y sus prácticas, y el entrelazamiento del mercado, el Estado y la lógica de la necesidad de la población por resolver su necesidad de vivienda (Abramo 2009, 2012'). No

1 Pedro Abramo (2012) precisa que existen dos modelos de la ciudad moderna: 1) mediterráneo, caracterizado por una urbe compacta y crecimiento intensivo; y 2) modelo anglosajón, donde el uso del suelo se da de manera difusa y mediante un crecimiento extensivo. El funcionamiento del mercado de suelo en las ciudades de América Latina hace que haya una estructura de ciudad compacta y difusa al mismo tiempo, una ciudad COM-FUSA. El mercado formal produce un tipo de ciudad compacta y difusa, mientras que el funciona- 
obstante, en la actualidad, ya no se trata de la preponderancia de invasiones de tierras basados en la necesidad de vivienda, sino en la lógica vital de acumulación (Gagó, 2015). Los mercados ilegales componen una vía de acceso al suelo urbano, producto de la instauración del modelo neoliberal, caracterizada por el desarrollo del mecanismo del despojo y una sociedad fragmentada.

La producción de una sociedad fragmentada es expresada en la interconexión de tres economías: formal, informal y la economía delictiva, como parte de los efectos del modelo neoliberal (Durand, 2007), y marcada por una cultura de transgresión generalizada hacia las reglas. Estas economías operan abiertamente en todas las ciudades y zonas del Perú. Si bien tienen su propia dinámica y orden interno, operan todas en un mismo mercado y en un mismo territorio; poseen vasos comunicantes, donde determinados agentes operan en más de una, pasan de una a otra, o aprovechan su existencia según les convenga a sus objetivos y estrategias de sobrevivencia. Según Francisco Durand (2007), esta sería efecto de los siguientes factores: primero, crecimiento demográfico que funciona más como un elemento que acelera la acción de los otros factores causales, en especial a partir de los sesenta la población peruana empieza a crecer y empieza a concentrarse en el ámbito urbano, generando presiones sobre el mercado de trabajo formal; segundo, la cultura de transgresión entendida como la violación o la ignorancia de la normatividad y se reflejada en las figuras del "achorado", "chonguero", "conchucodo", "mosca", "vivo" y "criollo", aceleró el desborde del control estatal, del mercado formal de trabajos y de las reglas sociales y valores de convivencia; tercer, la crisis del populismo en medios de una serie de crisis, estancó el mundo formal y abrió las puertas al desarrollo de la informalidad y la economía delictiva; cuarto, la falta de modelos de modernización alternativos en las épocas de crisis y posteriores a ellas; quinto, las condiciones de globalización económica que generan una competencia fuerte de todos contra todos y donde el capital extranjero tiene grandes ventajas frente al nacional, ya que el Estado peruano ha sido reducido en su capacidad por la mala aplicación del liberalismo en el país y está capturado por un grupo pequeño de corporaciones extranjeras que no dejan a otras empresas nacionales participar de las oportunidades del mercado mundial; y finalmente, el sexto, el mal gobierno, característico de las últimas décadas, que no ha podido realizar las reformas necesarias contener el desarrollo de las economías informales y delictivas.

miento del mercado informal del suelo también produce una ciudad informal compacta y difusa. Y existen dos submercados de suelo informal urbano: 1) submercado de lotes y 2) submercado en los asentamientos populares informales consolidados (API), y los dos submercados informales producen una estructura que como consecuencia expresan precarización del hábitat y de la reproducción de la vida popular. 
Además, como señala Julio Calderón (2016), la principal responsabilidad del Estado es que se convirtió en un promotor de asentamientos informales con la Ley de Barrios Marginales de 1961, a partir del cual reconoció a este tipo de asentamientos, acción pionera en toda América Latina, pero con el tiempo generó mayor número de ocupaciones por medio de la invasión y la ocupación gradual que contiene y mediante acciones que incluyen ilegalidad y clandestinidad, sobre todo en espacios periféricos de la ciudad, y lo que ha producido una tendencia preponderante de políticas correctivas antes que las preventivas, es decir, antes que desarrollar mecanismos que buscan adelantarse a la ocupación informal por la vía de acceso al suelo, se han extendido mecanismos y procedimientos que buscan formalizar e implementar servicios elementales después de realizada la ocupación. El surgimiento, consolidación y predominio de la ciudad ilegal tiene una relación directa con las políticas urbanas implementadas durante la década del sesenta, produciendo, además, prácticas clientelares en la relación entre el Estado y la población de estas márgenes.

El carácter fragmentado de la sociedad es también resultado de un proceso de producción de la ciudad sin políticas de desarrollo urbano definidos que contengan básicamente formas integrales de acceso a suelo urbano y política de vivienda social, lo que ha producido una expansión urbana sobre las tierras productivas de manera ilimitada y descontrolada. En ese sentido, desde fines de los setenta e inicios de los ochenta, la expansión urbana de Lima estuvo acompañada por el proceso de desestructuración de las cooperativas mediante la parcelación de las cooperativas agrarias $^{2}$, condicionando la configuración de la dinámica del sistema inmobiliario que se hizo más intensiva con implementación de políticas neoliberales a partir de los noventa.

Los inicios del siglo XXI estuvieron marcados por un intenso crecimiento de Lima Metropolitana, la reducción de áreas agrícolas, debido al surgimiento de nuevos asentamientos urbanos mediante el tráfico de tierras ${ }^{3}$ y los programas de las empresas inmobiliarias que han adquirido significativa importancia en la

2 Mediante el Decreto Legislativo 2, del 17 de noviembre de 1980, el segundo gobierno de Fernando Belaunde Terry permitió la parcelación de las cooperativas agrarias formadas durante la Reforma Agraria desarrollada por el gobierno de Juan Velasco Alvarado. "A partir de ese momento, el proceso de parcelación tomó un ritmo imparable y como resultado, en junio de 1990, de un universo de 609 cooperativas agrarias, de las cuales 596 eran de producción, se habían parcelado un total de 472 cooperativas ( 339 con proceso regular aprobado, 47 parceladas en proceso de regularización y 86, parceladas de hecho)" (Thays 1996: 35).

3 Para los procesos de ocupación de tierras en Lima Norte, también véase el trabajo de los historiadores Edgar Quispe y Santiago Tácunan (2002). A pesar de sus particulares actuales propiamente comerciales, es importante precisar que las apropiaciones ilegales de las tierras del Estado no son recientes, sino forman parte de nuestra historia. En ese sentido, Manuel Antonio Vásquez (2020) trabaja la usurpación de territorios del Estado en Puente Piedra, en el siglo XIX, por hacendados de esos tiempos. 
extensión de la urbe y la transformación periurbana. Este proceso ha implicado una especulación en los precios del suelo urbano con tendencia ascendente y la condena a los ocupantes finales pobres a ocupar los terrenos más distantes y difíciles de habitar que los condiciona a una mayor precariedad y que en conjunto producen una mayor fragmentación urbana.

La instauración de políticas neoliberales, acompañada de procesos históricos mencionados, fomentó el individualismo en todo nivel de la escala social. Se extendió la lógica de acumulación y la primacía del pragmatismo individual por encima de acciones colectivas, constituyendo subalternos autónomos, esto es, sujetos que construyen sentidos de libertad y autonomía teniendo como recurso las relaciones clientelares. Es decir, la especificidad de los subalternos autónomos en la urbe se hace inteligible a partir de la autonomía que tienen para decidir en qué espacio moverse mientras construyan redes clientelares; sin embargo, están atrapados en una lógica de vida al que le han dado sentido. Sus límites surgen cuando estas redes se disuelven. Las decisiones que toman tienen límites; la autonomía es existente siempre y cuando su condición de cliente sea importante para el otro con quien ha construido una red clientelar. Una evidencia clara es, por ejemplo, la ruptura de los vínculos de los sujetos que componen la red clientelar por la falta de la fluidez de las transacciones y los intercambios de favores.

Los subalternos autónomos forman parte de una lógica de dominación, es decir, constituyen parte de relaciones de poder y de ciertas jerarquías que construyen en un mundo donde, en apariencia, tienen las opciones de decidir, pero cuya representación de autonomía solo adquiere mediante el mecanismo del discurso y al asumir las reglas de juego de la sociedad hegemónica. Lo cierto es que en el mundo social, ellos piensan y hacen lo que no desean, viven en un contexto donde los hechos sociales se imponen y donde las reglas de juego impuestas, tanto por la política y la historia, se vuelven preponderantes. Las condiciones económicas que presentan no permiten situarse en espacios que desean, pero al mismo tiempo producen estrategias y mecanismos que les permite la acumulación de terreno y de enriquecimiento.

Gayatri Chakravorty Spivak (1998: 18) dice lo siguiente respecto al subalterno: "Esto es lo que había que decir, entonces, acerca del grupo considerado un amortiguador social. Para el "verdadero" grupo subalterno, cuya identidad es la diferencia, no hay, en rigor, sujeto subalterno irrepresentable que pueda conocer y hablar por sí mismo."

En ese sentido, en estos contextos de procesos de urbanización, los subalternos tienen autonomía mientras estén de acuerdo con las reglas juego, esto 
es, cuando pueden actuar de acuerdo a los contextos y con los elementos que les proporciona la sociedad. La materialización de sus objetivos está mediada por las redes clientelares que ellos mismos construyen, porque son conscientes de las limitadas opciones que tienen. Pueden ser autónomos y decidir por cualquiera de las alternativas de las reglas de juego impuestas, es decir, tienen la capacidad de construir estrategias con fines de beneficiarse con las alternativas que se muestran, por lo que de manera ideológica no podemos dejar de lado su subordinación por parte de las mismas reglas de juego. Esto quiere decir que el sujeto subalterno puede hablar pero no lo que desean sino lo que puede y debe hablar de acuerdo a las condiciones sociales y materiales del contexto histórico que ha reconceptualizado e interiorizado.

Las redes clientelares pueden servir como mecanismos claves para que sus voces sean escuchadas y sus objetivos sean materializados y concretizados. Se trata de sujetos sin referentes políticos e ideológicos determinados, únicos, y comportan un amplio sentido pragmático de la vida, entienden la política no desde el sentido ético sino desde una perspectiva estratégica, funcional a sus intereses particulares. Los subalternos autónomos mantienen alto grado de flexibilidad, no se definen como parte de algún grupo político, pero el contexto donde se mueven está tejido por grandes diferencias económicas y socioespaciales. Viven en un asentamiento urbano, como una asociación, pero no sienten parte de una entidad organizada, $y$ al que también pueden dejar en cualquier momento, por lo que la organización urbana resulta siendo cada vez más efímera, proclive a una fragmentación. Constituyen subalternos autónomos todos aquellos sujetos urbanos y periurbanos que no tuvieron "éxito", los que "no pudieron hacerlo" en la sociedad neoliberal, limitados por el mercado y por el Estado, constituyen pequeños microempresarios, ambulantes, autoempleados, desempleados, traficantes de tierras circunstanciales, tercerizados, quienes han vivido en cuartos alquilados, en casas de familiares, miembros de familias disfuncionales, etc. Sin embargo, se encuentran incorporados en las actividades estales como los procesos electorales y son estas actividades las que son utilizadas como momentos en que sus mecanismos pueden tener mayor resultado para tener conexión con los agentes del Estado. Estas conexiones se desarrollan en un contexto que mixtura tráfico de tierras por mafias organizadas, precariedad, loteos, programas inmobiliarios, formalización de asentamientos urbanos, procesos electorales, organización urbana, actividades económicas de supervivencia y la transformación de áreas productivas periurbanas. 


\section{Prácticas y estructuras clientelares: operadores y satélites personales}

Las relaciones clientelares pueden ser definidas como relaciones informales de intercambio recíproco y mutuamente benéfico de favores entre dos sujetos, basadas en una amistad instrumental, desigualdad, diferencia de poder y control de recursos, en las que existe un patrón, quien proporciona bienes materiales, protección y acceso a recursos diversos, y un cliente que ofrece a cambio servicios personales, lealtad, apoyo político o votos (Audelo, 2004; Auyero, 2001). Es una red de solución de problemas que juegan alrededor de un referente. Estas no son estructuras congeladas, sin temporalidad; tampoco son el resultado intencionado de la acción calculada, planificada y/o cínica de un político, sino producto de interacciones regulares, las cuales, si bien normalmente inauguradas por un "favor fundacional", deben ser cultivadas y practicadas de manera constante (Auyero, 2001). Sin embargo, la canalización de los recursos y los favores que benefician a los patrones y clientes no son de manera directa, sino que se encuentras intermediadas por un conjunto de agentes urbanos que, finalmente, influyen en el modelado de la ciudad popular y la conversión del espacio rural en espacio urbano (Capel 2013).

Hay autores (Auyero 1997, 2002; Auyero y Benzecry 2016; Sahlins 1979) que han demostrado que la estructura de la relación clientelar puede extenderse a la presencia de otros sujetos, por ejemplo, mediadores, "círculo íntimo" o "satélites

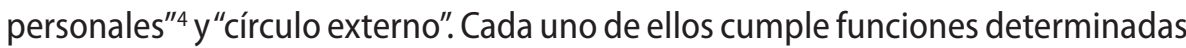
dentro de esta relación.

Los mediadores buscan clientes y patrones, median entre el patrón y algunos de sus seguidores. Han adquirido diferentes denominaciones de acuerdo a espacios y tiempos históricos: capituleros en el Perú de la década de los treinta y cuarenta, cabo eleitoral en el Brasil desde los treinta en adelante, gestor, padrino político, o cacique en México en varios momentos de su historia moderna, precinct captains en las máquina políticas de Chicago y otras grandes ciudades estadounidenses, caudillo barrial en los partidos radical y conservador en la Argentina de los años veinte y treinta, referente o puntero peronista en la Argentina de los noventa (Auyero 2002: 38). Como señala Auyero, a pesar de diferencias significativas entre ellos, su función es esencialmente la misma, intermedian entre el patrón y el cliente, operan como mediadores entre el político y las bases. Hoy, en el Perú, adquiere bastante significado el término "operador" para referir a aquellos que intermedian y construyen vínculos entre dos o más organizaciones políticas, instituciones, patrón/cliente, etc.

4 Categoría usada por Marshall Sahlins (1979). 
El "círculo íntimo" lo constituyen lazos más cercanos del mediador, sea de amistad o por razones de parentesco. Para el caso de la Argentina peronista, Auyero decía que el "círculo íntimo" "ayuda a los mediadores a resolver los problemas cotidianos de los habitantes de la villa: son quienes manejan los comedores infantiles que funcionan en las UBS, están encargados de abrir, cerrar, limpiar y mantener en orden el local, anuncian a los miembros de lo que podríamos llamar el "círculo externo" cuando el puntero está disponible en la UB, y "pasan la voz" cuando hay distribución de mercadería en la UB o en la municipalidad" (Auyero 2002: 39). En tanto, el "círculo externo" son potenciales de las capacidades distributivas del mediador. Está relacionado con referentes por medio de lazos débiles. "En otras palabras, los lazos que vinculan a los mediadores con su "círculo íntimo" son densos e intensos; en cambio, los que establecen con el "círculo exterior" son más ocasionales e intermitentemente activados" (lbíd.).

Estos agentes intercambian recursos de acuerdo a sus intereses, pues se guían por una lógica pragmática, de modo que buscan satisfacer sus intereses con el menor costo. Además, este intercambio depende de las posiciones de poder en las que se encuentran de modo que están sujetos al poder político formal (en el caso de las instituciones), y de los contactos que tengan (dirigencias y satélites personales), principalmente.

En las asociaciones urbanas, el "círculo íntimo" lo pueden constituir los coordinadores de los sectores, quienes mantienen vínculo directo con los miembros de la directiva que hacen de mediadores con los políticos. No obstante, estas relaciones tienden a ser efímeras, pueden mantenerse por un cierto tiempo y luego disolverse. Incluso pueden derivar en conflictos y rupturas de la asociación.

Los satélites personales, que pueden estar encargados de comedores populares, protegen siempre su posición y de mostrar aparente lealtad. Esta estructura, diseñada para idear el mejor funcionamiento de la red clientelar y de los propósitos clientelistas, al mismo tiempo puede generar "dificultades políticas, principalmente a la hora de organizar grandes masas de gente para la consecución de unos fines colectivos" (Sahlins, 1979, p. 273). Esto sobre todo porque genera un hábito en la población urbana de movilizarse de manera estratégica y calculada al interés económico individual. El prestigio de los mediadores obedece al poder de influencia de los satélites personales, debido a que trabajan al interior de un espacio reducido que les permite mantener un contacto directo con los posibles clientes.

Asimismo, el prestigio del satélite personal y de los dirigentes de asentamientos urbanos puede ser extendido pero luego también estigmatizada por 
sus intereses y actos de malversación y tráfico de terrenos, estigma que se extiende también hacia sus seguidores. Se puede saber sus malos manejos pero cuando se hace público todos sus actos, socialmente es flagelado, hundido o simbólicamente inexistente. Y en este marco de competencia, otro busca ocupar el liderazgo y así también cumplir sus objetivos. Esto es el momento de la fragilidad de la autoridad (Gluckman, 2009), en el que se "recibe muy poca o ninguna autoridad por atribución social: el liderazgo es una creación, una creación de los seguidores" (Sahlins, 1979, p. 273-274). El puesto del líder puede ser deseado por otro, incluso a partir de la formación de un bloque disidente con fines de formar una nueva organización independiente. Estas fracturas y lazos efímeros en las relaciones clientelares reflejan que las asociaciones urbanas se convierten en campos de conflicto y en áreas de competencia electoral, en un mercado de voto. Por estas razones, los bloques disidentes no cuestionan a la estructura en la que se desenvuelven sino a la persona que ocupa el cargo, por lo que "lejos de destruir el orden social establecido, trabajan en forma tal que incluso dan apoyo a este orden" (Gluckman, 2009, p. 58).

Mientras los regalos y bienes estén a disposición y, por ende, mayor cantidad de dinero, los hace más visible e interesante para que los clientes potenciales puedan buscar construir una red. Aquí, la vida social va tomando la figura y sentido del mercado, donde el intercambio es de votos y favores. El dirigente de la asociación tiene una alta movilidad, su autoridad proviene de su capacidad de gestión y de su capacidad para tejer relaciones clientelares con patrones "claves". Sin embargo, los cargos principales son sucedidos por miembros de la misma directiva, ya que formar parte de ella es una forma de captación de oportunidades, una línea de acumulación a la que Verónica Gagó denominó como "lógica barroca", una pragmática marcada por la condición neoliberal (Gago, 2015, p. 304). Los vínculos entre los dirigentes anteriores y los nuevos hacen que los mecanismos de manejo, distribución de los lotes y la gestión para el proceso de formalización del asentamiento sean indisociables de manera constante del tráfico de terrenos y la construcción de redes clientelares. Además, en estas asociaciones el dar, recibir y devolver no siempre se cumplen, por lo que vuelve en una incertidumbre, por lo menos temporalmente.

La estructura de la red clientelar en estas asociaciones, por consiguiente, puede tener doble efecto: fortalecer la figura de los mediadores y patrones, y desestructurar la asociación, hacer perder el poder de la directiva. Como las relaciones son efímeras y se sostienen bajo relaciones de amistad laxas, la desestructuración ha tendido ser el más frecuente. Los mediadores y patrones imaginan que solo se da 
el primero o que siempre es más efectivo (su propio fortalecimiento). Los satélites personales no siempre obedecen las decisiones de los mediadores, ni de los patrones, pero en el contacto demuestran habilidades de liderazgo, manejo de grupo, dominio de la oratoria, manejo del lenguaje y relación de confianza, aunque también existen aquellos que han tenido un trabajo más sostenido durante años en otros asentamientos urbanos.

La estructura de la red clientelar en la asociación, comporta, y está pensada, en tanto una relación funcional: los satélites personales pueden asegurar mayor número de votantes y seguidores, rapidez en la distribución de los bienes. Si esta relación funcional no tiene eficacia por medio de favores, privilegios o bienes, puede generar descontento en los clientes y en los satélites personales $y$, por consiguiente, se produce la ruptura de la estructura clientelar. La búsqueda de satélites personales son estratégicos, casi siempre están en su sector o comité, mientras que los mediadores pueden incluso no pertenecer a la asociación urbana pero proveen de bienes y conectan con autoridades y líderes de organizaciones políticas.

Mientras los satélites personales, al menos de manera temporal, sirven para una mayor conexión con los miembros de la asociación, los mediadores sirven para una mayor conexión con los patrones y la búsqueda de nuevos patrones. Una conexión estrecha entre el mediador y el patrón en el poder municipal puede permitir una mayor eficacia en la gestión de servicios y obras. Lo que se ha podido apreciar en otros asentamientos del distrito de Carabayllo es que el gobierno local hace que postulen sus más cercanas amistades en las organizaciones barriales, lo que no siempre tiene resultados favorables, pero las obras municipales se gestionan y se ejecutan de acuerdo a esa red existente entre ellos. Lo que se evidencia es que los patrones (políticos sobre todo) son visitantes temporales. Los clientes no manejan una relación estrecha de ningún tipo con el patrón, razón que explica también la alta movilidad de los clientes.

Los satélites personales operan en el nivel más reducido del asentamiento urbano, mientras los mediadores buscan reclutar satélites personales, clientes y patrones en el nivel más amplio y externo. Los satélites personales son considerados por los mediadores como puntos de apoyo político para buscar clientes y votos y para la distribución de la asistencia con esos fines.

En lo que respecta a los asociados y miembros de asentamientos urbanos, algunos pueden moverse a la posición de satélites o dirigencias tomando en cuenta las redes de contacto y el capital político que posean. No obstante, el común de ellos se encuentra en situaciones de vulnerabilidad y pobreza de modo que, para su supervivencia y procesos de movilidad social, consideran necesarias las prácticas 
asistencialistas y no dudan en apoyar a dirigentes y satélites a cambio de beneficios como comida, programas sociales, trabajo y lote.

Finalmente, la forma cómo se construyen las relaciones clientelares desde las bases también sugiere que, a diferencia del siglo XX (Auyero, 2001; Collier, 1978), se trata de un clientelismo de baja graduación, en el que los políticos o los agentes del Estado ya no pueden establecer ciertas condiciones pero ya no imponerlas de manera coercitiva. Son contextos en que el clientelismo político no es solo organizado ni diseñado desde el Estado, como sucedía, por ejemplo, en los cincuenta con el gobierno de Odría, en los setenta con Velasco ochenta durante el del APRA y con el fujimorismo durante los noventa; sino que esto ha adquirido sentido en la vida cotidiana de los sujetos de estos asentamientos urbanos.

\section{Tráfico de tierras: agentes y dinámicas}

El valor de cambio del suelo es aprovechado por los habitantes de la periferia urbana sin hacer uso residencial de los mismos. Tienen conocimiento de que la propiedad aumentará de precio conforme pasen los años y se adquieran servicios e infraestructura en la zona. Se evidencia la consideración de los lotes como recurso, principalmente económico, pues su venta otorgaría ingresos que complementarían aquellos recibidos por sus empleos, y muchos agentes mantienen conexión con la pobreza y el desempleo. El tráfico de terrenos es una lógica económica basada en la posesión del espacio (terrenos del Estado, privados y de la comunidad campesina) para la mercantilización y acumulación de dinero. Tiene diversos mecanismos, desde el uso de herramientas legales e ilegales, y puede involucrar a diversos agentes e implicar niveles de especialización.

Los sujetos que practican el tráfico de tierras recurren a diferentes mecanismos de negociación así como al uso de la violencia. Las invasiones no están directamente asociadas a la necesidad de la vivienda, por lo que los procesos de tomas de tierras y la formación de asociaciones se encuentran cercados por intenciones y acciones de enriquecimiento, estando los sujetos que practican dentro o fuera de la asociación.

Se puede decir que existe la presencia de diversos agentes y mecanismos a partir de los cuales se lleva a cabo la práctica del tráfico de terrenos que incluye introducirse como dirigentes de los asentamientos urbanos, traficantes en sí (externos), como miembros de las comunidades campesinas, posesión de un terreno de modo temporal en las asociaciones, entre otros, que es objeto de esta parte del artículo. Debe entenderse que esta clasificación es una aproximación metódica, 
con fines de entender los diferentes procesos y mecanismos que se construyen en estos escenarios.

\subsection{Dirigentes traficantes}

Son agentes urbanos que han formado parte de las invasiones y llegan a asumir responsabilidades al interior de las asociaciones urbanas, así como de las cooperativas agrarias en proceso de descomposición. Logran integrar la junta directiva con fines de tener mayores facilidades y vender terrenos de manera abierta o secreta, ya que son quienes todo el sistema de información de las áreas que comprende el asentamiento urbano y lo que fue la cooperativa agraria. La formación de la asociación no solo se da con personas que participan en el proceso de la toma de tierra o invasión, sino que, posteriormente a este proceso, siguen llegando otros sujetos que deben inscribirse ante la junta directiva después de pagar cierta cantidad, establecida por la dirigencia y la asamblea.

Los dirigentes, en tanto, pueden lograr tener acuerdos entre ellos para beneficiarse con los ingresos recaudados por las inscripciones de los nuevos sujetos que van llegando a la asociación. Cada sector de un asentamiento puede contar con un coordinador. Los coordinadores de los sectores pueden estar también involucrados en el tráfico de terrenos, al igual que otros dirigentes que incluso ya cuentan con propiedades en otros lugares de la ciudad, lo que explica que las asociaciones pueden estar siendo instrumentalizadas para el enriquecimiento individual que, finalmente, coadyuvan a la fragmentación de las asociaciones urbanas y vuelven lentos los procesos de gestión para su formalización.

Los desacuerdos por estos temas pueden generar rupturas entre los mismos dirigentes, ocasionando incluso a que se formen otras asociaciones propiciadas por aquellos que no lograron sus objetivos de acumular terrenos y dinero, así como manifiesta el relato de un informante:

[...].Todos habíamos cumplido aunque unos que otros solo habían pagado la mitad pero la mayoría pagó, entonces, sin haber ni empezado lo que es la lotización ellos ya habían empezado con la compra del terreno, supongo que pensaron "a ellos ahorita los agarramos y van a empezar a depositar lo que es para la compra del terreno". Nosotros nos dimos cuenta cuánto dinero está quedando en el banco y ellos no están haciendo nada y si ellos están comprando el terreno con qué dinero lo están comprando, fuimos investigando todo eso; más de cuarenta mil soles se había depositado en esa cuenta para lotización, ahora aparte estaban las cuotas pequeñas no se cuentan porque no hay documento que acredite nuestro aporte y 
ya más adelante cuando se divide la asociación Nadine Heredia hasta los mismos dirigentes también empezaron a dividirse y ya ahora solamente están dos, el presidente y la secretaria, los demás ya no existen ${ }^{5}$.

Los espacios dirigenciales de las asociaciones urbanas han devenido en espacios de negociación de lotes, donde los instrumentos para la formalización, reconocimiento y urbanización del asentamiento como la visación del plano, lotización, los certificados de posesión y cuotas vecinales, se convierten también en herramientas para acumular dinero en beneficio de un grupo dirigente vinculado al tráfico de terrenos. "Ahora lo agarramos" expresa los mecanismos intempestivos a los cuales recurren los dirigentes para realizar negociaciones con otros traficantes más especializados que se presentan como dueños de los terrenos y supuestos miembros de las comunidades.

El control del sistema de información hace que puedan disponer de los terrenos. A partir de este mecanismo, lo colectivo es utilizado para un privilegio organizado. El estatuto del asentamiento urbano queda sin efecto porque la misma población no es capaz de denunciar. Muchos pueden saberlo pero prefieren el silencio porque realizar la denuncia puede significar la pérdida de "apoyo", esto porque muchas familias que participan en invasiones, o llegan posteriormente, están conectadas con la precariedad y la pobreza, y buscan asegurar un lote con el supuesto apoyo de los dirigentes.

El dirigente traficante es un agente del mercado ilegal de tierras, es un agente de la oferta y tiende a actuar con racionalidad económica; moviliza fuerzas y acciones con la finalidad de institucionalizar la lógica del mercado y la mercantilización del espacio desde su presencia en la dirigencia y estructura organizacional de los propios asentamientos urbanos, consolidando una forma dominante del acceso al suelo en las periferias urbanas mediante el uso de la necesidad de residencia o de vivienda de los "usuarios finales" (Morales $s / f$ ), y donde terrenos comunales, privados y del Estado pueden ser vistos como móviles de acumulación y de la "redistribución económica en favor del capital (conocida como economía de la oferta)" (Brenner, Peck y Theodore 2015: 214), pero que genera como producto una desigualdad socioespacial y polarización social en donde la coerción y la violencia delictiva adquieren sentido que deviene en la desestabilización de la organización social urbana, así como de su capacidad de resistencia frente a los mecanismos de coerción de otros agentes, y condiciona la construcción de redes clientelares que aparecen como hábitos y compromisos tomados por las mismas bases sociales ante

5 Entrevista a miembro de la Asociación Juventud Solidaria de Carabayllo, febrero de 2016. 
la urgencia de buscar la regularización de sus predios. Puede subyugar a la población a las fuerzas del mundo delictivo y del mercado ilegal de tierras. Las acciones del dirigente no son ajenas a los procesos de urbanización y de gestión, conviven junto a estos contextos y procesos de regularización, pero imponiendo límites para el no avance de los mismos. Es decir, el dirigente traficante puede operar como barrera para la formalización y regularización del asentamiento urbano ocupado y como un desestabilizador de la organización social urbana expresados en fragmentaciones constantes y persistentes, como una oportunidad para continuar no solo con la mercantilización del suelo sino con la construcción de una incertidumbre de los actores sociales usuarios y la instrumentación de la colectividad en función de lo individual.

El dirigente traficante, en resumen, puede desplegar un abanico de mecanismos como cumplir el rol de mediación ${ }^{6}$ entre usuarios finales y otros agentes traficantes de mayor rango para tener múltiples posibilidades de ganancia, reclutar a la población para promover ocupaciones informales, insertarse como representante de la organización urbana, arreglos y alianzas con traficantes y empresas inmobiliarias, búsqueda de arreglos con posesionarios originales del lote, constituir un bloque coercitivo y operar como barrera para que el asentamiento se mantenga en condiciones informales para continuar con la mercantilización del suelo y la instrumentación de la colectividad en función de lo individual que en conjunto reproducen una incertidumbre en usuarios que ocupan el lote.

En el Perú, en paralelo a dirigentes de asentamientos urbanos de origen informal, los dirigentes de las cooperativas agrarias, también, se convirtieron en agentes del mercado de suelo, lo que facilitó el proceso de parcelación de las tierras agrícolas y la formación de nuevos agentes urbanos especializados en el financiamiento y la promoción inmobiliaria. Y naturalmente, además de la pérdida de confianza en la estructura dirigencial, desencadenó en conflictos y tensiones entre los parceleros y los dirigentes de la cooperativa, por la ausencia de balances sobre su la gestión dirigencial, la venta ilegal de áreas no ocupadas, estado de las parcelas (proceso de adjudicación, titulación y los ingresos recibidos por estos servicios), copia actualizada del padrón de asociados, información de adjudicatarios y compradores desde el ingreso como dirigentes y la tergiversación en el otorgamiento de las escrituras y las constancias por la venta de terrenos remanentes de la cooperativa agrícola.

Estas trasformaciones en las bases sociales y la presencia de una alta demanda del suelo urbano han llevado a la constitución de lógicas y formas de relación

6 En el Perú muchos dirigentes barriales han devenido en convertirse en "testaferros" de alcaldes/traficantes y otros agentes del mercado ilegal de tierras. 
que legitiman la producción de diferencias socioespaciales, fracturan la tenencia colectiva y profundizan la ruptura de organizaciones urbanas, todo esto en un escenario de procesos de neoliberalización. Las ilusiones de familias que aún no han logrado la tan anhelada casa propia o la adquisición del lote para hábitat, viene siendo aprovechada por sujetos para mercantilización de la tierra por medio de mecanismos ilegales, tanto en los procesos de urbanización mediante programas inmobiliarios en zonas agrícolas como en ocupaciones en zonas no productivas.

\subsection{Tráfico de tierras por comuneros}

Más de una decena de distritos de Lima Metropolitana se expanden por laderas que forman parte de territorios comunales que constituyen zonas no productivas. Estas comunidades campesinas pasan por una fragmentación que hace que el tráfico de terreno sea una de las prácticas constantes sobre su territorio.

La fragmentación de la propiedad comunal es por la presencia creciente de tomas de tierras informales y la formación de nuevos asentamientos urbanos que en principio tomaron contacto con la comunidad para legitimar la posesión, se convirtieron en anexos y luego terminaron por dominar el territorio bajo diversos mecanismos. Además, está relacionada con la desestructuración de la organización matriz debido a la independización de nuevas formaciones urbanas para formar entidades distintas, con normas, reglas de juego propias y autonomía en sus decisiones, lo cual significó la desestabilización de la organización interna de la comunidad matriz y el surgimiento de múltiples organizaciones y dirigencias paralelas en nombre de la comunidad, que empezaron a tener mayor protagonismo y obstruyeron las funciones de la organización original tanto en la administración de los terrenos como en la articulación de los miembros.

Cuando se dan ocupaciones informales, quienes se presentan como comuneros no son los de la comunidad matriz sino de los anexos urbanos independizados; pero muchas de estas nuevas organizaciones se encuentran en condiciones de ilegalidad, sin reconocimiento y vinculadas incluso a actos delictivos como el tráfico de terrenos. Hoy existe tensión y conflicto de la comunidad matriz con estas diversas organizaciones y entre estas últimas. Sin embargo, es preciso mencionar que en algunos casos, la creación de nuevos asentamientos fue promovida por la organización de la misma comunidad matriz con la finalidad de preservar su integridad territorial (Gutiérrez 1998) por la amenaza cada vez mayor de ocupaciones informales, la expansión urbana y el predominio de lógicas mercantiles a partir de la implementación de las políticas neoliberales. 
Las evidencias etnográficas sugieren que muchos sujetos optan por el mecanismo de presentarse como comuneros y dirigentes de la comunidad ante las personas y grupos que ocuparon las zonas no productivas; e intentan negociar para el pago por los terrenos ocupados, lo que puede motivar la formación de una comisión de asociados que busquen negociar con los supuestos dueños de las tierras. El propósito es lograr vender las tierras invadidas, aunque en primer momento pueden intentaron usar la violencia como medio para el desalojo de los invasores, así como señala nuestra informante:

Cuando el grupo llega por primera vez a esta zona, la comunidad de Jicamarca, en realidad la gente de Jicamarca dijeron que iban a venir matones y en cierta parte si vinieron con matones, con camionetas a botar a la gente, pero como había un gran número en los cerros y todos estaban ya ubicados pues se pusieron bien bravos, le dieron con palo, escopeta, cohete, todos así, estaban armados también para enfrentarse y les corretearon a toditos los que vinieron, hasta que se fueron.?

Nuestra informante narra la forma cómo llegaron a la asociación los supuestos miembros de la comunidad campesina de Jicamarca aludiendo que eran dueños de las tierras tomadas con la finalidad de establecer contrato con los asociados.

Supuestamente un señor que tiene sus documentos, tiene sus papeles, vino con un documento diciendo que era el dueño, pero no estaba inscrito en registros públicos y es por eso que la gente no quiso pagar, pero si él hubiera tenido reconocido quizás sí pagaba, porque la gente sí estaba de acuerdo a no tener enfrentamiento y pagar su derecho a quien tenga sus papeles al día, pero como él no tuvo, el pueblo no le pagó.

Aparecieron diferentes "dueños", uno y otro, uno y otro; eran traficantes de terrenos. De ahí se forma la asociación para que nos respalde, pero qué nos han respaldado, más nos han robado dinero hasta el día de hoy8.

Muchos miembros de la asociación incluso tienen conocimiento de los traficantes. Por ejemplo, uno de nuestros informantes hizo mención de una familia de la Comunidad Campesina de Jicamarca dedicada al tráfico de tierras y que tuvo mucha incidencia cuando se invadió y formó la asociación:

7 Entrevista a miembro A de la Asociación Juventud Solidaria de Carabayllo, febrero de 2016.

8 Entrevista a miembro B de la Asociación Juventud Solidaria de Carabayllo, febrero de 2016 
La familia, que te digo, son comuneros de Jicamarca. Ellos también son otros traficantes que nos querían botar y querían cobrar una suma de tres mil nuevos soles por lote, pero no nos hemos dejado y hasta ahora por eso seguimos luchando. ${ }^{9}$

De acuerdo a las disposiciones de la ley de Titulación de las Comunidades Campesinas de la Costa, Ley $N^{\circ} 26845$, los comuneros poseedores de tierras comunales pueden acordar el régimen de la propiedad de las tierras que ocupan. En ese sentido, los comuneros poseedores por más de un año, podrán solicitar la adjudicación a título de propiedad de las tierras que conducen, y para ello se requiere el voto a favor de no menos de la mitad de los comuneros poseedores de un año, asistentes en la Asamblea. Además, para la adquisición en propiedad que ocupan terceros poseedores por un período no menor de dos años sin relación contractual, se requiere del voto favorable de no menos del treinta por ciento (30 \%) de los comuneros calificados de la comunidad, asistentes a la Asamblea General. Adoptado el acuerdo de adjudicación, el Proyecto Especial de Titulación de Tierras y Catastro Rural (PETT) del Ministerio de Agricultura, procedería a la elaboración de los planos catastrales y de las memorias descriptivas correspondientes. El representante legal, dentro del plazo de quince (15) días hábiles de recibidos los planos y memorias descriptivas, procederá a otorgar los respectivos contratos de transferencia de los derechos de propiedad. Sin embargo, estos mecanismos de adjudicación vienen siendo utilizados para la mercantilización de terrenos por miembros de estas comunidades. Como se ha señalado, esto se debe a cómo se encuentra la estructura de las comunidades en áreas de expansión urbana, en especial de la costa, y la forma cómo han sufrido una desestructuración de su organización matriz a partir de la formación de otras organizaciones urbanas desconectadas de la organización matriz producto del crecimiento urbano.

\subsection{Miembros temporales: domingueros}

Para este mecanismo, el sujeto debe lograr primer la inserción en la asociación urbana. Predomina la lógica de la posesión no para la residencia o vivencia sino para la transferencia. Participan de la invasión y toman un lote, lo que será delimitado y adecuado, "pampeado", para que sea vendido posteriormente, porque saben que el valor de cambio aumenta con el tiempo, más aún si este lote es trabajado y adecuado. Este mecanismo de negociación es lo que se conoce como "traspaso", forma de intercambio en que el propietario inicial recibe dinero del comprador por

9 Entrevista a miembro C de la Asociación Juventud Solidaria de Carabayllo, febrero de 2016. 
el tiempo de trabajo realizado, es decir, el lote se convierte en una mercancía y para el beneficio individual. Este hecho es de conocimiento de la mayoría de la población, incluso de los propios dirigentes. Las tensiones dirigenciales y problemas dentro de la asociación urbana pueden ser utilizadas como parte del discurso que justifique la transacción, es una clave que usan de manera frecuente las personas que están temporalmente en la asociación. Algunos pobladores acumulan terrenos incluso bajo el supuesto de reservar lotes para familiares, pero luego destinan para la venta. Después de la venta de sus lotes, estos sujetos se desvinculan casi por totalidad del asentamiento urbano, generando asentamientos y terrenos deshabitados.

Algunos han vendido sus terrenos. Bastante, a ocho mil soles, cinco mil, se vendieron y otra gente que tiene paga pues. Así. Hay bastantes chozas vacías. En esta zona vivimos quince personas. Los domingos vienen todos y el resto no viene. Ahora otra gente quiere entrar. Buena hora sería que entre a los lotes vacíos. ${ }^{10}$

Uno de los hechos interesantes que se puede ver es que muchos de los socios de la asociación no residen en la asociación sino se encuentran solo los domingos. La verbalización de Angélica sintetiza de manera adecuada estas prácticas en contextos de división de las asociaciones. Las tensiones y conflictos por intereses entre los propios miembros de las juntas directivas pueden utilizado por muchos socios que finalmente se retiran de la asociación vendiendo el terreno que ocuparon en el proceso de invasión.

\subsection{Venta por beneficiarios de la reforma agraria}

Pequeños propietarios beneficiarios de la reforma agraria venden sus parcelas a empresas inmobiliarias para la construcción de espacios privados orientados a la mercantilización del ocio que "supone un aumento de la demanda de consumo y de espacios recreativos" (Capel, 2013: 183), la construcción o autoconstrucción de viviendas particulares y otras múltiples actividades asociadas a la vida urbana.

Después del proceso de individualización de la propiedad colectiva mediante la parcelación de la cooperativa, los beneficiarios de la reforma agraria adoptaron varias estrategias: arrendar la tierra, aliarse con empresas inmobiliarias externas para lotizar sus tierras agrícolas, retener suelo y retardar la venta para aumentar el precio del terreno. Pero también hay propietarios parceleros, sobre todo empresas inversionistas e hijos de los beneficiarios de la reforma agraria, que activan la venta

10 Entrevista a miembro D de la Asociación Juventud Solidaria de Carabayllo, febrero de 2016. 
de suelo sin estudios técnicos para el cambio de uso de agrícola a urbano, de modo que se encuentran fracciones de zonas agrícolas en convivencia con espacios en pleno loteo. En el proceso de lotización de las zonas agrícolas participan empresas inmobiliarias de mediano, pequeño y gran capital, pequeños propietarios de parcelas de manera individual y en sociedad, especuladores, hijos de parceleros que forman empresas inmobiliarias promotoras y constructoras, intermediarios, profesionales (ingenieros, geógrafos, arquitectos, abogados, etc.) y hasta dirigentes de cooperativas agrarias, notarios, además de municipalidades y de la Sunarp que tienen un papel fundamental en la aprobación e inscripción del cambio de uso, la habilitación urbana y el sistema del loteo.

La venta de las parcelas para la urbanización, la construcción de viviendas y la ampliación de espacios de ocio tuvo un incremento exponencial en los últimas dos décadas, unas veces de manera directa por los propietarios beneficiarios de la reforma agraria y, otras, por empresas inmobiliarias que adquirieron la tierra para el desarrollo de programas inmobiliarios, siendo los terrenos de más alto precio los cercanos a las carreteras y a la urbe consolidada, pero sin cumplir ningún "requisito de urbanización que incluye accesibilidad, pavimentación, pistas y veredas, iluminación y los servicios de agua y desagüe y finalmente la inscripción del inmueble en registros públicos, sino solo con luz provisional y agua mediante camión cisterna. El valor de las tierras lotizadas es más alto que el valor de la tierra agrícola adquirida, lo que significa que la tierra puede multiplicar su valor por el simple "cambio de uso" (Capel, 2013, p. 79) y la lotización. Los precios de los terrenos lotizados se manejan desde una lógica especulativa por la alta demanda existente y la ausencia de una regulación del mercado de suelo, favorecidos por el predominio de la idea "dejar hacer y dejar pasar". Las empresas administradas por los hijos de los parceleros, generalmente, van a la zaga de los inversionistas en cuanto a precios de los terrenos, mucho más baratos, y muestran "flexibilidad en los pagos".

\subsection{Traficantes "en si"}

Son traficantes propiamente dichos, profesionales y vinculados a la estructura delictiva que operan"sobre la base de la violencia y corrupción" (Durand, 2007, p. 90). No mantienen vínculos directos, ni por razones de parentesco ni por amistad, con los pobladores de la organización urbana, sino utilizan la coerción en gran medida para el logro de sus objetivos. Pueden presentarse como dueños de los espacios ocupados u organizar tomas de tierras, muchos de ellos buscando sorprender con el uso de la violencia y una alta capacidad represiva. Los mecanismos de apropiación 
de los terrenos por parte de estos sujetos preceden a la invasión de terrenos y a la formación de los asentamientos urbanos de una forma sistemática.

Constituyen mafias organizadas que manejan grandes negocios de terrenos en muchas partes de la ciudad y territorios periurbanos, generando un escenario de temor y miedo con la finalidad de que los miembros de los asentamientos urbanos puedan aceptar pagar por los terrenos ocupados. Es decir, las invasiones pueden ser una buena oportunidad para los traficantes en sí, oportunidad en el sentido de que pueden vender los terrenos de su supuesta propiedad. Los mismos traficantes pueden ser promotores de las tomas de tierras y casi siempre con resultados favorables. Un mecanismo efectivo es la producción de la violencia sin dejar de lado la opción de persuadir para que los invasores mediante un acuerdo puedan pagar por las tierras ocupadas. Esto dependerá de los cálculos que pueda tener el traficante de terrenos.

Las tensiones que se generan en estos escenarios llevan a ciertas confusiones de los pobladores, que pueden, en cierta medida, decidir por salir de esos sobresaltos: algunos pagando a los traficantes el valor formulado del terreno ocupado, así como enfrentarse en los propios invasores y entre estos y sus dirigentes. Existen acusaciones a los dirigentes por aliarse con los traficantes. Los traficantes "en si" también toman también la clave de haber comprado los terrenos a la comunidad campesina

Los traficantes pueden tejer toda una red y así uno de los sujetos cercanos puede interceder cuando ellos decidan no presentarse directamente ante los pobladores. Los traficantes en sí son muy conscientes de las prácticas que realizan, llegando a un alto de profesionalización y desarrollando vínculos y habilidad que les permita operar en diversas áreas periurbanas de la ciudad. La profesionalización de estos sujetos se sustenta en el hecho de que tanto los instrumentos de producción de violencia como sus intermediarios (una suerte de operadores), que son principalmente parientes, se sostienen de manera planificada. Estos sujetos definen en buena medida la organización del territorio bajo sus propias reglas que se sostienen en la lógica enriquecimiento.

\subsection{La venta de tierra pública por las propias autoridades}

En las últimas décadas, varios alcaldes distritales han sido allanados y enjuiciados penalmente no solo por corrupción, sino también por su relación con el tráfico de terrenos, usurpación de propiedades públicas y privadas, sicariato y crimen organizado. En un primer momento, estos hechos evidencian que la producción y gestión de la ciudad y la práctica política vienen siendo presididas por el delito, 
mediante la formación de redes delictivas que constituyen organizaciones que operan desde diversos niveles sociales, lo que hace ver que es un fenómeno estructural y sistémico, en que los involucrados materializan sus propósitos con un manejo del sistema de información que produce el propio Estado, fundamentalmente disposiciones normativas y legales vinculadas con la formalización y titulación de los predios urbanos y rurales. La producción y gestión de la ciudad se mezcla con prácticas delictivas que en muchos casos son organizadas, mediadas y operadas por los mismos agentes del Estado, desde las mismas instituciones públicas como las municipalidades locales, así como por las formas de organización social reconocidas por el Estado en colusión con sujetos vinculados a lo delictual.

La presencia de proyectos inmobiliarios ha implicado la disputa entre organizaciones delictivas vinculadas al tráfico ilegal de tierras en colusión con autoridades municipales y comunales. Si hacemos una comparación, entre el tráfico de terrenos promovido y organizado por sujetos que operan desde el poder municipal y el tráfico de terrenos promovido por dirigentes de asentamientos urbanos, puede resultar una primera diferencia: Desde el primer nivel existe una mayor facilidad para su formalización que solo desde el segundo nivel.

Además, a partir del ingreso de traficantes al poder local, existe un manejo de todo el sistema de información municipal, así como la facilidad de los procedimientos de formalización de la posesión de los predios. Estamos frente a la relación de fenómenos de tráfico de terrenos, corrupción, clientelismo y criminalidad. La red del tráfico de terreno articula agentes y actores, pero, al mismo tiempo, articula modos de delito, modos de ocupación, fuerzas de choque, comportamientos, reglas, lógicas y estrategias e intercambios económicos. Condicionan sistemas de vida desiguales y expresados en la falta de acceso de servicios elementales, instituciones públicas y espacios de socialización.

\subsection{Tráfico de terrenos por miembros de asentamientos consolidados}

Las zonas periféricas pueden ser usadas para establecer ampliaciones de zonas urbanas ya consolidadas, donde llegan familias conectadas por lazos de amistad y de parentesco a las situadas en zonas consolidadas, donde son los dirigentes de estos asentamientos los que propician las ampliaciones porque implican una oportunidad para traficar terrenos. Además de este fenómeno, las evidencias actuales nos sugieren que en estas periferias urbanas en muchos casos ya no se opta por la formación de ampliaciones, sino son tomas de tierras que tienen el propósito de realizar loteos tizados para luego ponerla en venta. 
Estas nuevas ocupaciones pueden ser realizadas por agentes vinculadas al desempleo, pero en general se trata de jóvenes y personas vinculadas a un empleo de baja remuneración o desempleadas que viven en las partes bajas consolidadas. Los agentes no necesariamente están vinculadas a una mafia organizada pero sí en el pasado constituyeron parte de pandillas que tenían una lógica de diferencia barrial, pero que ahora se encuentran disueltas. Pero sí se trata de jóvenes conectados con la lógica del lote como recurso, donde la acumulación prima por encima de vivienda. Ya no se busca la formación ampliaciones de bloques consolidados, porque implicaría seguir las reglas de juego marcados por la directiva y de la organización urbana, por lo que prefieren formar una ocupación desligada y nueva con su propia denominación, lo que desenvuelve una serie de tensiones y conflictos entre quienes forman parte de estos procesos.

El modus operandi consiste en organizar una ocupación de áreas no productivas y baldías que forman parte de territorios comunales adyacentes a zonas urbanizadas mediante el reclutamiento de familias de las partes bajas. Las ventas se encuentran a cargo de un responsable del grupo organizador de la toma. El propósito es vender lotizaciones tizadas y sin servicios, por lo que formar un comité o junta directiva no es funcional y evitan en todo momento el establecimiento de reglas, bases, normas y estatutos que limiten sus acciones.

\section{A modo de reflexión final}

Como bien hemos señalado al principio, este artículo se ha basado en el propósito de entender las prácticas del tráfico de terrenos y la dinámica de las prácticas clientelares en las periferias urbanas, conteniendo las diferentes relaciones entre los sujetos sociales, tanto en el mercado de suelo urbano como en los espacios de formación de los nuevos asentamientos urbanos por medio de ocupaciones de territorios comunales, espacios no productivos y pequeñas parcelas agrícolas de beneficiarios de la reforma agraria.

La ausencia de un proyecto de ciudad, la falta de una ley de suelo, la naturalización del reconocimiento de la posesión del lote y no el acceso a vivienda, la desestructuración de la organizacional comunal y la apropiación de la lógica mercantil de las políticas económicas neoliberales son elementos indisociables del tráfico de tierras, la especulación inmobiliaria y la extensión de la estructura clientelar que acoge una serie de tejidos sociales que penetran el propio comportamiento y hábito de las personas con intereses particulares asociados sobre todo al poder 
económico, generando formas de organización social urbanas más efímeras y proclives a fragmentaciones continuas.

Como síntesis de la especificidad y la complejidad de actitudes, mecanismos y pensamientos de los sujetos que actúan en un escenario difuso y en proceso de formación de asentamientos urbanos, se plantea el concepto de subalternos autónomos que compone términos que son adjetivos y sustantivos al mismo tiempo, y cuyo sentido es sobre todo relacional e histórico. La especificidad de los subalternos autónomos en la urbe se hace inteligible a partir de la autonomía que tienen para decidir en qué espacio moverse mientras construyan redes clientelares; sin embargo, están atrapados en una lógica de vida al que le han dado sentido. Sus límites surgen cuando estas redes se disuelven. La autonomía es existente mientras sus condiciones de cliente sea importante para el otro con quien han construido una red clientelar. Una evidencia palpable es la ruptura de los vínculos de los sujetos que componen la red clientelar por la falta de la fluidez de las transacciones y los intercambios de favores. Los subalternos autónomos forman parte de una lógica de dominación, es decir, constituyen parte de relaciones de poder y de ciertas jerarquías que construyen en un mundo donde, en apariencia, tienen las opciones de decidir, pero cuya representación de autonomía solo adquiere mediante el mecanismo del discurso y al asumir las reglas de juego de la sociedad hegemónica. Constituyen subalternos autónomos todos aquellos sujetos urbanos y periurbanos que no tuvieron "éxito" en la sociedad neoliberal: pequeños comerciantes, ambulantes, auto empleados, desempleados estructurales, traficantes circunstanciales, quienes han vivido en cuartos alquilados, en casas de familiares, miembros de familias disfuncionales, etc. Aunque no estén en el poder, sin embargo, se encuentran incorporados en las actividades estatales como los procesos electorales, actividades utilizadas como espacios en que sus mecanismos pueden tener mayor resultado para mantener conexión y con los agentes del Estado y recibir bienes, servicios y privilegios.

Las evidencias sugieren que las relaciones clientelares se extienden y grafican la participación de diferentes agentes: políticos, mediadores, satélites personales, clientes, autoridades municipales, entre otros. El voto (acto estatal) y la disposición a la asistencia mediante redes clientelares ha adquirido sentido en la vida cotidiana de los sujetos. Las relaciones clientelares pueden ser definidas como relaciones informales de intercambio recíproco y mutuamente benéfico de favores entre dos o más sujetos, basadas en una amistad instrumental, desigualdad, diferencia de poder y control de recursos. Pero no solo los políticos buscan tener clientes, mediadores y aliados políticos en los asentamientos urbanos, sino también los mismos miembros de estas organizaciones han interiorizado estas prácticas y tienden a construir sus 
redes como mecanismos efectivos para lograr objetivos, bienes, servicios y privilegios. La forma cómo se construyen las relaciones clientelares desde las bases también sugiere que, a diferencia del siglo XX, se trata de un clientelismo de baja graduación, en el que los políticos y/o el Estado pueden poner ciertas condiciones pero no imponerlas de manera coercitiva. Son contextos en que el clientelismo no es organizado ni diseñado desde el Estado, como sucedía en los cincuenta con Odría, en los ochenta con APRA y en los noventa con el fujimorismo.

El tráfico de tierras no puede ser entendida fuera de la realidad en la que se encuentra inscrita, ya que profundiza las limitaciones de acceso general al suelo urbano. De manera similar que en las prácticas clientelares, los agentes que participan en este fenómeno cuentan con intermediarios que reproducen las acciones de violencia contra quienes tienden a apropiarse los espacios que se encuentran dentro de sus expectativas, o a tratar de negociar cuando ya se haya concretado la toma de tierras. Los intermediarios pueden mantener una red de parentesco 0 de amistad, y tienen el propósito de resolver lo que consideran como "problema". El tráfico de tierras es practicado por diversos sujetos participantes de las mismas invasiones (pobladores, coordinadores, dirigentes, etc.) o supuestos comuneros de áreas aledañas a la Metrópoli limeña, además de la presencia de mafias organizadas que realizan actividades de tráfico de una manera más sistemática e implica un sistema de intercambio mediante una negociación coercitiva (cupos), donde el crimen parece convertirse en un acto consciente, desmedido y eficaz para lo que se encuentran dentro de este círculo.

\section{Bibliografía}

ABRAMO, P. (2009) La producción de las ciudades latinoamericanas: mercado inmobiliario y estructura urbana. Quito: OLACCHI.

ABRAMO, P. (2012) “La ciudad informal COM-FUSA: el mercado y la producción de la territorialidad urbana popular". En SALAZAR, C.E. (coord.), Irregular. Suelo y mercado en América Latina. México: El Colegio de México.

AUdelo, J. (2004) “¿Qué el clientelismo? Algunas claves para comprender la política en los países en vías de consolidación democrática." En: Estudios Sociales, vol. XII, núm. 24, pp.124-142.

AUYERO, J. (2002) "Clientelismo político en Argentina: doble vida y negación colectiva”. En: Perfiles Latinoamericanos, junio, número 020. México DF: Facultad Latinoamericana de Ciencias Sociales. Pp. 33-52. 
AUYERO, J. (2001) La política de los pobres. Las prácticas clientelistas del peronismo. Buenos Aires: Manantial.

AUYERO, J. y BENZECRY, C. (2016) “La lógica práctica del dominio clientelista”. En: Revista Mexicana de Ciencias Políticas y Sociales. Nueva Época, Año LXI, núm. 226. México DF: Universidad Nacional Autónoma de México. Pp. 221-246.

BRENNER, N.; JAMIE P. y THEODORE, N. (2015) “Urbanismo neoliberal. La ciudad y el imperio de los mercados", en Observatorio Metropolitano de Madrid (edit.), El mercado contra la ciudad. Sobre globalización, gentrificación y políticas urbanas. (Madrid:Traficantes de sueños).

CALDERÓN, J. (2016/2005) La ciudad ilegal. Lima en el siglo XX. Lima: Punto Cardinal Editores. CAPEL, H. (2013) La morfología de las ciudades. III. Agentes urbanos y mercado inmobiliario. Barcelona: Ediciones del Serbal.

CollieR, D. (1978) Barriadas y élites: de Odría a Velasco. Lima: Instituto de Estudios Peruanos.

Del CASTILlo, L. (2004) “Conflictos en tierras de Comunidades Campesinas y legislación”. En Alejandro

DURAND, F. (2007) El Perú Fracturado: Formalidad, informalidad y economía delictiva. Lima: Fondo Editorial del Congreso del Perú.

GAGO, V. (2015) "La razón neoliberal". En: Ante la máquina: para salir del consenso desarrollista. 1a ed. Ciudad Autónoma de Buenos Aires: Tinta Limón.

GUTIÉRREZ, B. (1998)“Jicamarca: (des)control de su territorio comunal". Revista Investigaciones Sociales, Vol. 2, Número 2.

GLUCKMAN, M. (2009) “La fragilidad en la autoridad”. En: Costumbre y conflicto en África. Lima: UNMSM/UCH.

MARTUCCELLI, D. (2015) Limay sus arenas. Poderes sociales y jerarquías culturales. Lima: Cauces Editores.

MolinA, J. y VALENZUELA, H. (2006) Invitación a la antropología económica. Barcelona: Bellaterra.

MORALES, C. (2005ª) “Curar o vacunar, dos políticas en tensión: la regularización vs las reservas territoriales en el desarrollo urbano sustentable".

MoRALES, C. (2005b) "Conceptos avanzados del suelo urbano". Texto preparado para el curso de Educación a Distancia sobre Planeación Urbana y Gestión del Suelo en Ciudades Mexicanas.

MORALES, C. (2017b) "Subalternos autónomos transformaciones periurbanas y tráfico de tierras en el contexto de una sociedad de mercado: Carabayllo, Lima". Tesis de Licenciatura en Antropología. Lima: UNMSM. 
QuIJANO, A. (2014).“Dependencia, cambio social y urbanización en Latinoamérica”. En: Cuestiones y Horizontes. De la Dependencia Histórico-Estructural a la Colonialidad/ Descolonialidad del Poder. Buenos Aires: Clacso.

QUISPE, E.y TÁCUNAN, S. (2002). El Cono Norte de Lima. Pasado, presente y futuro de Carabayllo. Lima: Seminario de Historia Rural Andina, UNMSM.

Riofrío, G. y CABreRA, T. (2010). "Expansión urbana y comunidades campesinas". Revista Quehacer № 179.

SAHLINS, M. (1979). "Hombre pobre, hombre rico, gran hombre, jefe: tipos políticos en Melanesia y Polinesia". En J. R. LLobera (Comp.). Antropología política. Barcelona: Editorial Anagrama.

SPIVAK, G. C. (1998). "¿Puede hablar el sujeto subalterno?" Revisado 11/10/ 2014.

THAYS V., Luis Iván (1996). Evolución del mercado de tierras y tenencias. Lima: USAID/ Gobierno Peruano.

VÁsqueZ M., M. Antonio (2020). "Usurpación de tierras del Estado en Puente Piedra”. En: Punchaw. Revista de Investigaciones Sociales y Culturales. Lima: CEPIS. 